\title{
Performance of a drop-in biofuel emulsion on a single-cylinder research diesel engine
}

\begin{abstract}
Current targets in reducing $\mathrm{CO}_{2}$ and other greenhouse gases as well as fossil fuel depletion have promoted the research for alternatives to petroleum-based fuels. Pyrolysis oil (PO) from biomass and waste oil is seen as a method to reduce life-cycle $\mathrm{CO}_{2}$, broaden the energy mix and increase the use of renewable fuels. The abundancy and low prices of feedstock have attracted the attention of biomass pyrolysis in order to obtain energy-dense products. Research has been carried out in optimising the pyrolysis process, finding efficient ways to convert the waste to energy. However, the pyrolysis products have a high content in water, high viscosity and high corrosiveness which makes them unsuitable for engine combustion. Upgrading processes such as gasification, trans-esterification or hydro-deoxynegation are then needed. These processes are normally costly and require high energy input. Thus, emulsification in fossil fuels or alcohols is being used as an alternative.

In this research work, the feasibility of using PO-diesel emulsion in a single-cylinder diesel engine has been investigated. In-cylinder pressure, regulated gaseous emissions, particulate matter, fuel consumption and lubricity analysis reported. The tests were carried out of a stable non-corrosive wood pyrolysis product produced by Future Blends Ltd of Milton Park, Oxfordshire, UK. The product is trademarked by FBL, and is a stabilized fraction of raw pyrolysis oil produced in a process for which the patent is pending. The results show an increase in gaseous emissions, fuel consumption and a reduction in soot. The combustion was delayed with the emulsified fuel and a high variability was observed during engine operation.
\end{abstract}

Key words: pyrolysis oil, emulsion, wood pyrolysis, engine testing

\section{Introduction}

Global energy demand concerns and the increased levels of greenhouse emissions to the atmosphere, particularly $\mathrm{CO}_{2}$, have drawn attention into research for alternative energy vectors. Biomass has been broadly considered as an option due to its abundancy and availability all over the world, low prices, renewability and zero $\mathrm{CO}_{2}$ emissions while the use of waste materials such as, cooking oil has been studied as part of the solution for fossil fuels as well as to solve or palliate the uncontrolled disposal of these toxic substances [3].

Several techniques have been investigated to transform these waste materials and biomass into valuable biofuels: i) physio-chemical conversion processes, ii) biochemical conversion process and iii) thermochemical conversion processes [1]. Amongst thermochemical processes are pyrolysis, gasification and liquefaction [1, 4]. The advantages of pyrolysis over other techniques are the insignificant production of toxic components, less energy consumption and the solid waste formed is disposable [3].

Pyrolysis is the thermal decomposition of organic material in absence of oxygen [1-3,5]. It can be divided in conventional pyrolysis whether an electrical heating resistance is employed for the process or microwave pyrolysis, a more energy efficient approach [3]. The main products of the pyrolysis process are bio-oil, bio-char, methane, hydrogen, carbon dioxide and carbon monoxide [1,6]. The proportion of these products will depend on the feedstock, the technique/method used (temperature, heating ramp and residence time) $[2,7]$ and the feedstock pretreatments (thermal, biomass, chemical and physical) $[2$, $3,5]$ and therefore, no agreement is found in the literature in the products concentrations [3]. Depending on the technique, pyrolysis can be divided in slow, fast and flash pyrolysis [1, 2]. The resultant product will again depend on the trade-off between the temperature, heating rates, pressures, residence time leading to different biomass yield products [1-3]. Fast pyrolysis is currently the most widely used due to the high percentage of bio-oil, also known as pyrolysis oil (PO): 60\% yield in bio-oil, $20 \%$ biochar and $20 \%$ syngas [1].

However, the energy content of bio-oil compared to petroleum derived fuels is nearly half [1] or one third of the fossil fuels [8] , between $15-20 \mathrm{MJ} / \mathrm{kg}$ [2] due to the high water content, $30-40 \%$ [1]. Upgrading processes, such as stem reforming, gasification or transesterification are needed due to the high moisture, high viscosity, solid content, chemical instability and high corrosiveness [9]. Despite these disadvantages, lower toxicity products, good lubricity and greater biodegradation makes pyrolysis oil an attractive solution to petroleum depletion [10].

An alternative process to these upgrading techniques is emulsification of $\mathrm{PO}$ in diesel for use in compression ignition 
engines $[11,12]$. Frequently emulsions of standard pyrolysis oil contain substantial amount of water, have low calorific value, are unstable and have high particulate content [11, 12]. However, FutureBlends have developed an oil capable of improving or overcoming these drawbacks. The product is known as advanced pyrolysis oil (APO $\left.{ }^{\mathrm{TM}}\right)$.

Previous attempts to test PO in diesel engines showed limited operation time due to the poor volatility, high viscosity (up to 4 times higher than diesel [8]), high corrosiveness, cooking [8, 14] and low cetane number [8]. Yang et al. [15], fast-pyrolysed coffee bean residue to obtain a bio-oil which was emulsified with diesel at two different percentages: 5\% PO-95\% diesel and 10\% PO-90\% diesel. A reduction of $\mathrm{NO}_{\mathrm{x}}$ emissions was found when increasing the PO content. However, $\mathrm{CO}, \mathrm{CO}_{2}$ and smoke levels were higher when compared to diesel. The emulsified blends extended the ignition delay and the pre-mixed combustion, a typical trend when the fuel cetane number is reduced. Kim et al. [8] explored the direct use of wood pyrolysis oil on a single-cylinder diesel engine. With this aim, butanol was blended to reduce the viscosity of the fuel and $5 \%$ of two cetane improvers, polyethylene glycol 400 (PEG-400) and 2-ethylhexylnitrate (2-EHN) were added. Three percentages of PO were tested, 10\%, 20\% and $30 \%$ PO, the percentage of butanol was reduced without modifying the $5 \%$ content in cetane improvers. The results showed that the PO delayed the combustion and increased considerably the fuel consumption. Particulate number emissions were increased with the higher content in $\mathrm{PO}$ as well as unburnt hydrocarbons and $\mathrm{NO}_{\mathrm{x}}$ for the majority of the blends and engine conditions tested. A reduction in $\mathrm{HCs}$ and $\mathrm{CO}$ was reported at low engine loads (IMEPs) and the $30 \%$ blend was capable of reducing slightly $\mathrm{NO}_{\mathrm{x}}$ emissions. On the other hand, the thermal efficiency was improved around 3\% with the use of PO-butanol blends. Hossain [16] studied blends with dried digestate with butanol $(10,20$, $30 \%$ vol.) and waste cooking oil in a multi-cylinder diesel engine. The viscosity was reported to be 5-7 times higher and heating value $17 \%$ lower than diesel. The ignition delay was increased and the engine stability particularly at high loads as well as the thermal efficiency were affected negatively. $\mathrm{CO}$ emissions were reduced although $\mathrm{CO}_{2}$ and fuel consumption were increased up to $5 \%$ and $19 \%$ respectively on a volumetric basis. Smoke levels were reduced $44 \%$. The comparison between researches is therefore challenging due to the different feedstocks and approaches used to burn the PO in diesel engines and for these reasons, no agreement in the effect of PO in gaseous emissions or engine combustion is found.

The aim of this research work is to analyse combustion performance, gaseous emissions, particulate matter and lubricity of $\mathrm{APO}^{\mathrm{TM}}$ in diesel emulsion in a research single cylinder, direct injection, naturally aspirated compression ignition engine.

\section{Experimental set-up}

\subsection{Engine}

The engine used in this study is an air-cooled single cylinder, direct injection and naturally aspirated compression ignition engine. The experimental engine test rig consists of an air cooled Thringe Titan thyristor-type DC electric dynamometer coupled to a load cell to load and motor the engine. The standard injection timing is 22 Crank Angle Degree (CAD) Before Top Dead Centre (bTDC) as set by the manufacturer. The engine oil temperature, recorded using a K-type thermocouple, was used to check that the engine was fully warm as a means to reduce test-to-test variability. The technical data and engine characteristics are given in Table 1 . The in-cylinder pressure traces were acquired using a Kistler $6125 \mathrm{~B}$ quartz type pressure transducer with a Kistler 5011 charge amplifier at crank shaft positions determined using a 360-ppr incremental shaft encoder (Baumer BDK 1605A360-5-4). The data acquisition and combustion analysis were carried out using in-house (University of Birmingham) developed LabVIEW software running a National Instruments (PCI-MIO-16E-4) data acquisition board. Output from the analysis of engine cycles included the in-cylinder pressure, indicated mean effective pressure (IMEP), percentage coefficient of variation (COV) of IMEP values and percentage $\mathrm{COV}$ of peak cylinder pressures, average crank angle for ignition delay, and other combustion characteristic information. To reduce the noise in the data signals and acquisition system, the data is collected for a number of cycles (i.e. 100) and then averaged. The COVs of IMEP and peak cylinder pressure were used as criteria for combustion stability (cyclic variability). Fuel consumption was measured volumetrically.

Table 1. Engine specification data

\begin{tabular}{|l|c|}
\hline Number of cylinders & 1 \\
\hline Bore/stroke & $98.4 \mathrm{~mm} / 101.6 \mathrm{~mm}$ \\
\hline Displacement volume & $733 \mathrm{~cm}^{3}$ \\
\hline Compression ratio & $15.5: 1$ \\
\hline Rated power $(\mathrm{kW})$ & $8.6 @ 2500 \mathrm{rpm}$ \\
\hline Peak torque $(\mathrm{Nm})$ & $39.2 @ 1800 \mathrm{rpm}$ \\
\hline Injection system & Three holes pump-line-nozzle \\
\hline Injection timing $\left({ }^{\circ} \mathrm{bTDC}\right)$ & 180 \\
\hline Maximum injection pressure (bar) & Bowl-in-piston \\
\hline Engine piston & \\
\hline
\end{tabular}

\subsection{Fuel properties}

The tests were performed of a stable non-corrosive wood pyrolysis product produced by Future Blends Ltd of Milton Park, Oxfordshire, UK emulsified in diesel. The product is trademarked by FBL, and is a stabilized fraction of raw pyrolysis oil produced in a process for which the patent is pending. The components of the pyrolysis oil used to produce the the $\mathrm{APO}^{\mathrm{TM}}$ are presented in Table 2.

The values in Table 2 vary with the biomass feedstock used, the temperature and time of processing and the condensation methods used to quench the reaction. The values cited are in the middle range from many production experiments.

With almost 30\% mass fraction water, the higher heating value is similar to the starting wood at $15-17 \mathrm{MJ} \mathrm{kg}^{-1}$. However the high acid fraction makes for a $\mathrm{pH}$ of $<2.5$, and 
solid char and mineral matter makes the PO abrasive - with poor fuel qualities. Future Blends has followed a strategy of modifying the production and processing of the PO to improve the quality. APO ${ }^{\mathrm{TM}}$ is produced by a process that removes the sugar components (for sale as feedstock to produce ethanol), and retains the aromatic and phenolic based lignin fraction. The loss in yield relative to the original PO is partly compensated for, by the much higher high heating value of this fraction relative to the sugar fraction (27 MJ $\mathrm{kg}^{-1}$ vs $16 \mathrm{MJ} \mathrm{kg}^{-1}$ ).

Table 2. Component Fractions of Pyrolysis Oil meeting the requirements of ASTM D7544-12 Standard Specification for Pyrolysis Liquid Biofuel - Grades G and Grade D

\begin{tabular}{|l|c|}
\hline Components & Mass fraction (\%) \\
\hline Water & 27 \\
\hline $\begin{array}{l}\text { Ether soluble organics (aldehydes, ketones, } \\
\text { phenolicmonomers) }\end{array}$ & 21 \\
\hline Light fatty acids - mainly aceticacid (HAc) & 28 \\
\hline $\begin{array}{l}\text { Ether insoluble organics (anhydrosugars/oligo- } \\
\text { mers, hydroxy acidswith C > 10) }\end{array}$ & 15 \\
\hline $\begin{array}{l}\text { Lignin derivatives, polymerization products and } \\
\text { solids }\end{array}$ & 4 \\
\hline n-hexaneextractives - e.g. hydrocarbons, terpenes & \\
\hline
\end{tabular}

Both the hot vapour filtration and $\mathrm{APO}^{\mathrm{TM}}$ processes are the focus of current patenting action. In Table 3, the properties of APOTM are presented.

Table 3. APO ${ }^{\mathrm{TM}}$ Properties

\begin{tabular}{|l|c|c|}
\hline Property & Unit & Value \\
\hline Carbon & Mass fraction (\%) & 62.6 \\
\hline Hydrogen & Mass fraction (\%) & 7.4 \\
\hline Oxygen & Mass fraction (\%) & 30 \\
\hline $\begin{array}{l}\text { Higher Heating Value (HHV dry } \\
\text { basis) }\end{array}$ & MJ kg $^{-1}$ & 27.0 \\
\hline Water & Mass fraction (\%) & $<2$ \\
\hline Density & $\mathrm{kg} \mathrm{m}^{-3}$ & 1150 \\
\hline DynamicViscosity @ 40 degC & $\mathrm{mOH} \mathrm{g} \mathrm{kg}^{-1}$ & 270 \\
\hline TAN number & Mass fraction (\%) & 16 \\
\hline Conradson Carbon & Celsius & 70 \\
\hline Flash Point (estimated) & & \\
\hline
\end{tabular}

Stability tests were carried out for the $\mathrm{APO}^{\mathrm{TM}}$ and no changes in viscosity of the APO ${ }^{\mathrm{TM}}$ were found in 672 hours. In the standard corrosion test a polished mild steel rod is immersed in the material for 24 hours did not corrode.

Two batches of APO ${ }^{\mathrm{TM}} /$ diesel emulsions were provided to the University of Birmingham in order to analyse the performance of the fuel during engine operation. Gaseous emissions, PM emissions, volumetric fuel consumption and in-cylinder pressure were evaluated. Three engine conditions were selected: $1500 \mathrm{rpm}-8 \mathrm{Nm}, 1500 \mathrm{rpm}-15 \mathrm{Nm}$ and 1500 $\mathrm{rpm}-25 \mathrm{Nm}$. The blends tested are the following:

Batch (i): $20 \%$ APO, $8 \%$ surfactant and $72 \%$ diesel. The emulsion was prepared in a Silverston High Shear Mixer. The viscosity of the emulsification was too high for automotive applications. Therefore, in the following batches several APO $^{\text {TM }}$ percentages were tested.

Batch (ii): The concentration of APO ${ }^{\mathrm{TM}}$ in diesel fuel was modified in order to study the effect of fuel composition on engine stability: a) $15 \% \mathrm{APO}^{\mathrm{TM}}, 8 \%$ surfactant, $77 \%$ diesel and b) $20 \%$ APO $^{\text {TM }}, 8 \%$ surfactant, $72 \%$ diesel.

The base fuel used for both campaigns was an Ultra Low Standard Diesel (ULSD) provided by Shell Global Solutions, UK. Properties of the base fuels are summarised in Table 4.

Table 4. Properties of ULSD EN590 fuels. Batches (i) and (ii)

\begin{tabular}{|l|c|c|c|}
\hline Property & Method & Unit & Diesel \\
\hline Density at $15^{\circ} \mathrm{C}$ & DIN EN ISO 12185 & $\mathrm{~kg} / \mathrm{m}^{3}$ & 834.5 \\
\hline Kinematic viscosity at $40^{\circ} \mathrm{C}$ & DIN EN ISO 3104* & $\mathrm{mm}^{2} / \mathrm{s}$ & 2.78 \\
\hline CFPP & DIN EN 116 & ${ }^{\circ} \mathrm{C}$ & -27 \\
\hline Cloud Point & DIN EN 23015 & ${ }^{\circ} \mathrm{C}$ & -8 \\
\hline $50 \% \mathrm{v} / \mathrm{v}$ & DIN EN ISO 3405 & ${ }^{\circ} \mathrm{C}$ & 270.6 \\
\hline $90 \% \mathrm{v} / \mathrm{v}$ & DIN EN ISO 3405 & ${ }^{\circ} \mathrm{C}$ & 331.5 \\
\hline Lower Calorific Value & & $\mathrm{MJ} / \mathrm{kg}$ & 42.7 \\
\hline
\end{tabular}

\subsection{Emission analysis}

\subsubsection{Gaseous emissions}

A MKS MultiGAS 2030 FTIR analyser (Fourier Transform Infrared Spectroscopy) was used to analyse the gas components of the engine exhaust. To obtain the gas information, the FTIR analyser emits at once a beam that contains several frequencies of light to measure how much of that beam is absorbed by the sample then, the beam is modified to involve different combination of frequencies. This process will be repeated until the several data points have been scanned. These data points will be used to infer what the absorption (of the sample) is at each wavelength and therefore confirm the sample species. The MKS MultiGAS 2030 FTIR analyser is capable of measuring gaseous species including $\mathrm{NO}, \mathrm{NO}_{2}, \mathrm{~N}_{2} \mathrm{O}, \mathrm{NH}_{3}, \mathrm{HCs}, \mathrm{CO}, \mathrm{CO}_{2}$ and $\mathrm{H}_{2} \mathrm{O}$ (except for $\mathrm{N}_{2}, \mathrm{H}_{2}$ and $\mathrm{O}_{2}$ ).

\subsubsection{Particulate Matter}

A TSI scanning mobility particle sizer (SMPS) 3080 electrostatic classifier is employed to establish the particle size distribution. This is comprised of an electrostatic classifier series 3080, a 3081 Differential Mobility Analyser (DMA) and a model 3775 Condensation Particle Counter (CPC). The CPC that forms part of the SMPS system has a particle count accuracy of $\pm 10 \%$ for particle concentrations lower than $5 \times 10^{4}$ particles $/ \mathrm{cm}^{3}$ and $\pm 20 \%$ for particle concentrations lower than $10^{7}$ particles $/ \mathrm{cm}^{3}$. The flow rate and sheath rate were 6 and $0.6 \mathrm{~L} / \mathrm{min}$ respectively. The particulate size distribution obtained for these stings ranges from $10 \mathrm{~nm}$ to $406.8 \mathrm{~nm}$. The scan time is 120 seconds per sample. Hydrocarbon condensation and nucleation was minimised by controlling the temperature in the dilution process. 


\subsection{Lubricity analysis}

Lubricity properties of PO samples were performed on High Frequency Reciprocation Rig (HFRR). The schematic of the equipment is shown in Figure 1. The test specimens comprised of a $6 \mathrm{~mm}$ diameter steel ball and steel disc. All the tests were conducted according to the EN ISO 121561:2006 standard (ISO12156-1, 2006). The fuel temperature maintained at $60^{\circ} \mathrm{C}$ and the volume of the fuel was $3 \mathrm{ml}$. A humidity and temperature controlled cabinet was employed to assure the appropriate conditions of the sample according to the standards. During the test, the disc was fully submerged in PO while the upper specimen was loaded with a $200 \mathrm{~g}$ mass and subjected to a reciprocating motion with frequency of $50 \mathrm{~Hz}$ during 75 minutes $[17,18]$.

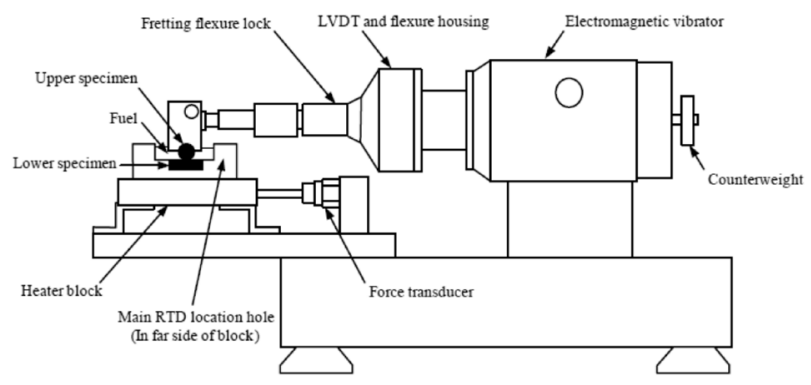

Fig. 1. Schematic Diagram of HFRR [18]

To investigate the wear scan diameter (WSD) of the ball in micrometres, an optical microscope was used together with 100x magnification lens. The average WSD was calculated and corrected to normalise for the standard water vapour pressure of $1.4 \mathrm{kPa}$. This considers the effect of the air conditions on the fuel's lubricating performance while the HFRR was operating, as defined by ISO 12156-1. The wear scan diameter was corrected considering the relative humidity and the temperature. All of the lubricity experiments were repeated twice and repeatability was demonstrated to be less than $20 \mu \mathrm{m}$. The equipment was calibrated prior the test to assure the accuracy of stroke length.

\section{Results}

\subsection{Combustion analysis}

The in-cylinder pressure recorded from the combustion of the two fuels at the three engine conditions is presented in Figure 2. For low loads ( 8 and $15 \mathrm{Nm}$ ) the pyrolysis blend reduced the pressure inside the combustion chamber, however, at the highest load the trend is reverted. The Coefficient of Variance (COV) of Indicated Mean Effective Pressure (IMEP) for the three engine conditions is presented in Figure 3. It can be noted that for 8 and $15 \mathrm{Nm}$, it was below $5 \%$ and similar to diesel. However, the stability at the highest engine load was above the acceptable limits.

The rate of heat release (ROHR) or fuel oxidation rates is proportional to the mass fraction burnt $(\mathrm{mfb})$ and describes the combustion history of the fuel. This parameter is also related to the local pressure and temperature conditions in the combustion chamber which govern the formation mechanism of the pollutant emissions. Figure 4 shows the results for the three loads, diesel and pyrolysis oil fuels. The PO blend delayed the start of the combustion and produced a higher peak at the beginning of the combustion, known as premixed combustion. Due to this high peak in heat release the local pressure and temperature conditions will promote the formation of $\mathrm{NO}_{x}$. Due to the higher viscosity and physical properties of the PO fuel the auto ignition is delayed leading to more premixed combustion and thus, $\mathrm{NO}_{\mathrm{x}}$.

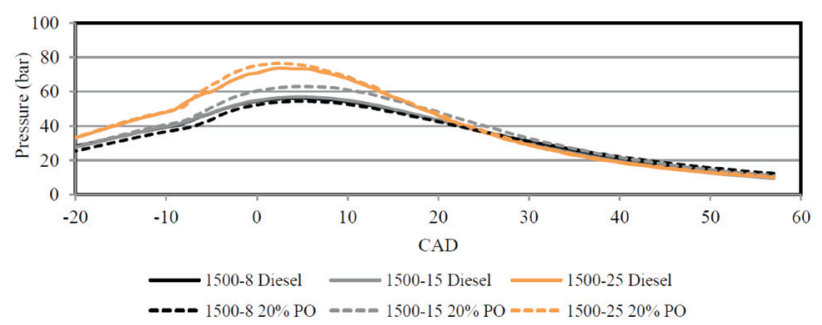

Fig. 2. In cylinder pressure results for diesel and pyrolysis fuel

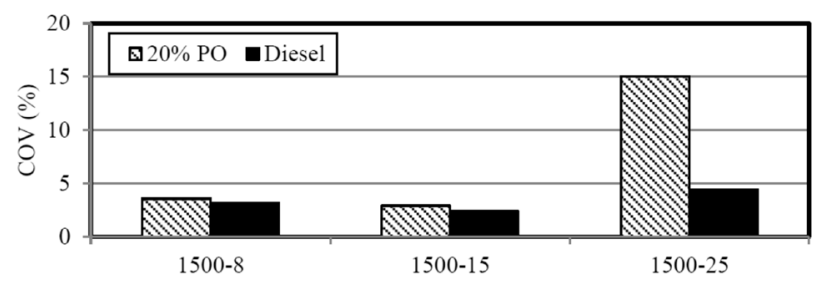

Fig. 3. COV of IMEP

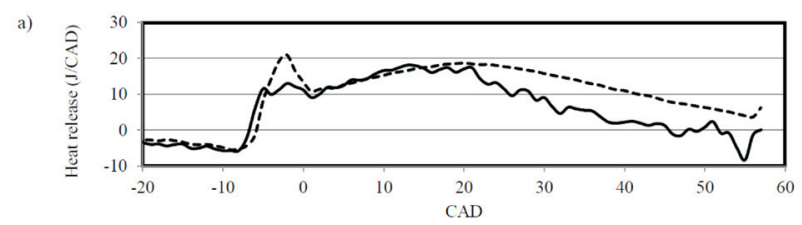

- 1500-8 Diesel ----- 1500-8 20\% PO

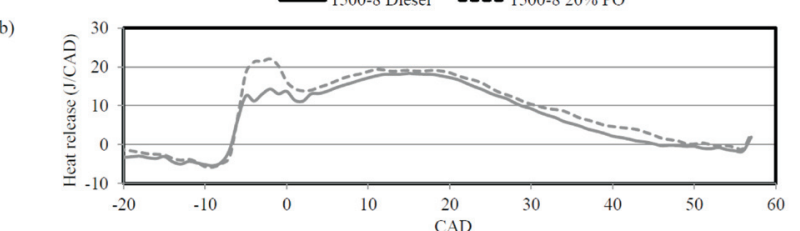

1500-15 Diesel $\quad=--=1500-1520 \%$ PO

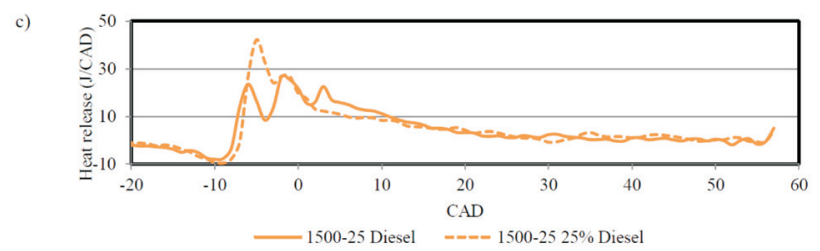

Fig. 4. ROHR: a) 1500-8, b)1500-15 and c) 1500-25 (rpm-Nm)

\subsection{Gaseous emissions}

\subsubsection{Batch (i)}

\section{$\mathrm{NO}_{\mathrm{x}}$ emissions}

Figure 5 presents the results obtained for $\mathrm{NO}_{x}$ emissions. As the engine load is increased, the NO levels are higher as the in-cylinder temperature and the fuel demand to achieve this condition are also higher. On the other hand, the trend in $\mathrm{NO}_{2}$ emissions is opposite, as the thermal conditions inside the cylinder favours the NO formation processes. $\mathrm{N}_{2} \mathrm{O}$ emissions are low for both fuels, although its emission must 
be considered due to its high greenhouse effect potential and detrimental effects on human health. The pyrolysis oildiesel blend shows to produce slightly higher levels of $\mathrm{NO}_{x}$ $\left(\mathrm{NO}, \mathrm{NO}_{2}\right.$ and $\left.\mathrm{N}_{2} \mathrm{O}\right)$ than the diesel fuel for all the studied conditions. The physical properties of the fuel (i.e. viscosity) play a significant role on fuel injection, atomization and vaporization processes and therefore, combustion and pollutant emission formation.

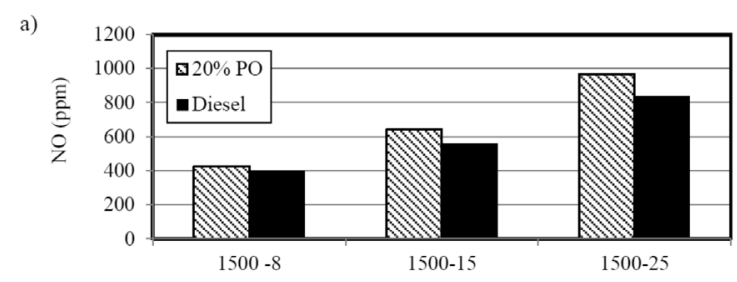

b)
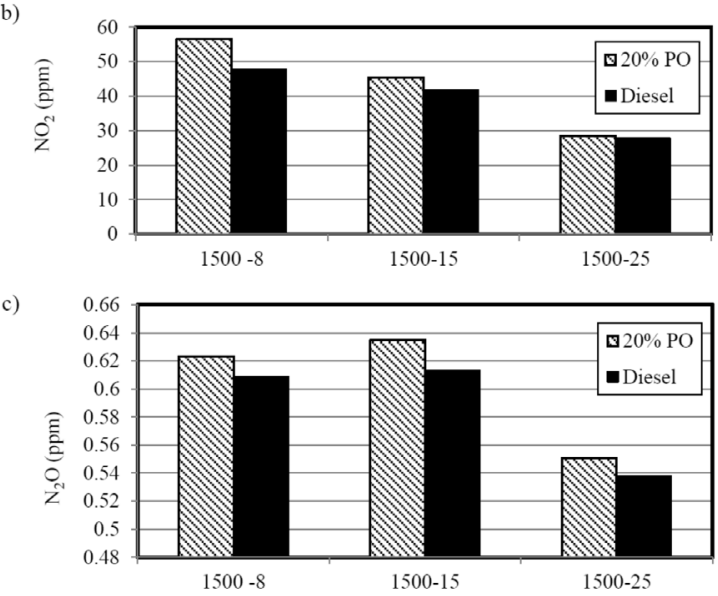

Fig. 5. $\mathrm{NO}_{\mathrm{x}}$ emissions: a) $\left.\mathrm{NO}(\mathrm{ppm}), \mathrm{b}\right) \mathrm{NO}_{2}$ (ppm and c) $\mathrm{N}_{2} \mathrm{O}$

\section{Carbonaceous gaseous emissions}

Similarly to $\mathrm{NO}_{\mathrm{x}}$ emission trends, the same trend was observed for $\mathrm{CO}$ and THC emissions, Figure 6. The combustion of the pyrolysis blend produced a larger amount of $\mathrm{CO}$ and also slightly increased concentration of unburnt

a)

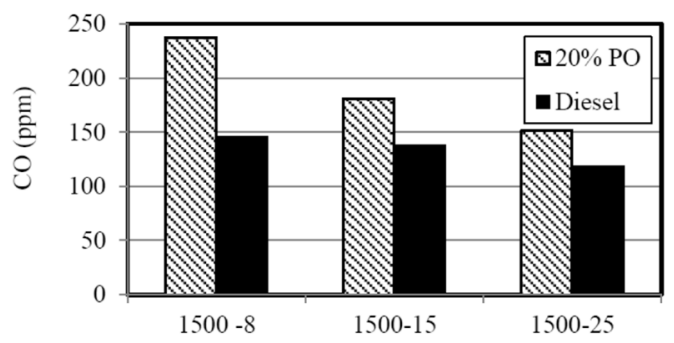

b)

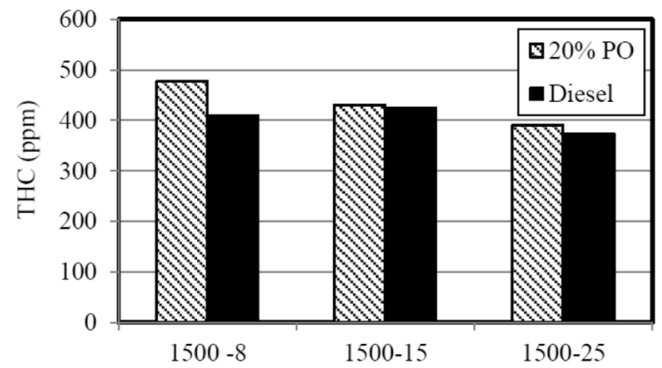

Fig. 6. CO emissions [ppm] and THC [ppm] hydrocarbons, particularly a low load where the combustion chamber is cold and the hence the available heat to drive the complete oxidation of fuel.

During the engine operation with the fuel blend some issues with the engine stability were noted. The engine torque and speed could not be maintained at the set-values. As a consequence, higher fluctuations in gaseous emissions were observed, particularly for THC. The comparison between diesel and PO THC emissions against time is depicted in Figure $7 \mathrm{a}$ and $\mathrm{b}$, respectively.

The presence of heavier HCs in the pyrolysis oil can lead to lower combustion efficiency and reduced engine thermal efficiency. In addition, fuel properties such as the lower calorific value of the oxygenated components can increase the fuel consumption. These reasons explain the increase in $\mathrm{CO}_{2}$ levels seen from the combustion of the pyrolysis blend, Figure 8 .

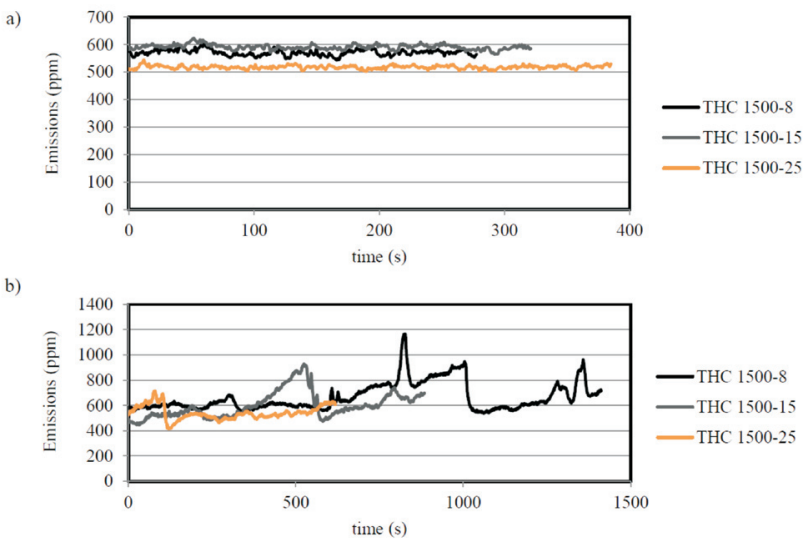

Fig. 7. THC against time: a) Diesel and b) Pyrolysis oil (PO)

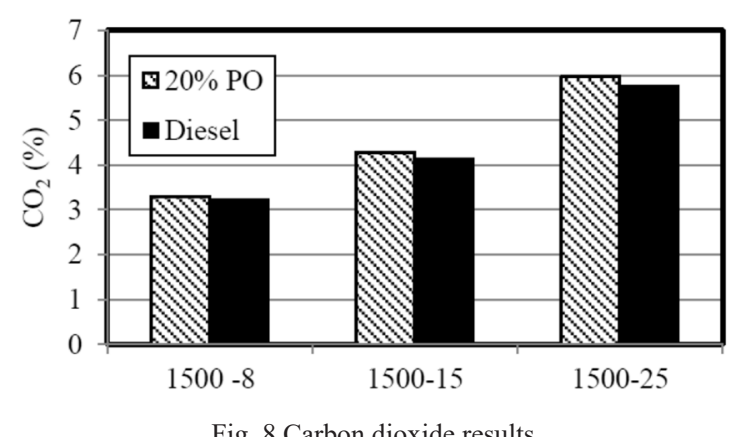

3.2.2. Batch (ii)

Similarly to the previous Batch (i), the combustion of the emulsified fuel resulted in an increase of $\mathrm{NO}, \mathrm{NO}_{2}$ and $\mathrm{N}_{2} \mathrm{O}$ emissions, Fig. 9. In general in addition to fuel chemistry (oxygen content and flame temperature) the modified combustion patterns obtained with the fuel blend (Fig. 4) can explain the increased $\mathrm{NO}_{x}$ emissions formation. Parameters such as fuel density, viscosity, heating value and distillation point are all affecting the injection timing, rate and fuel penetration.

Carbonaceous emissions

The combustion of pyrolysis blend increased the $\mathrm{CO}$ levels emitted when compared to diesel fuel, a trend that is similar to the earlier campaign (Fig. 10). Regarding THC, 

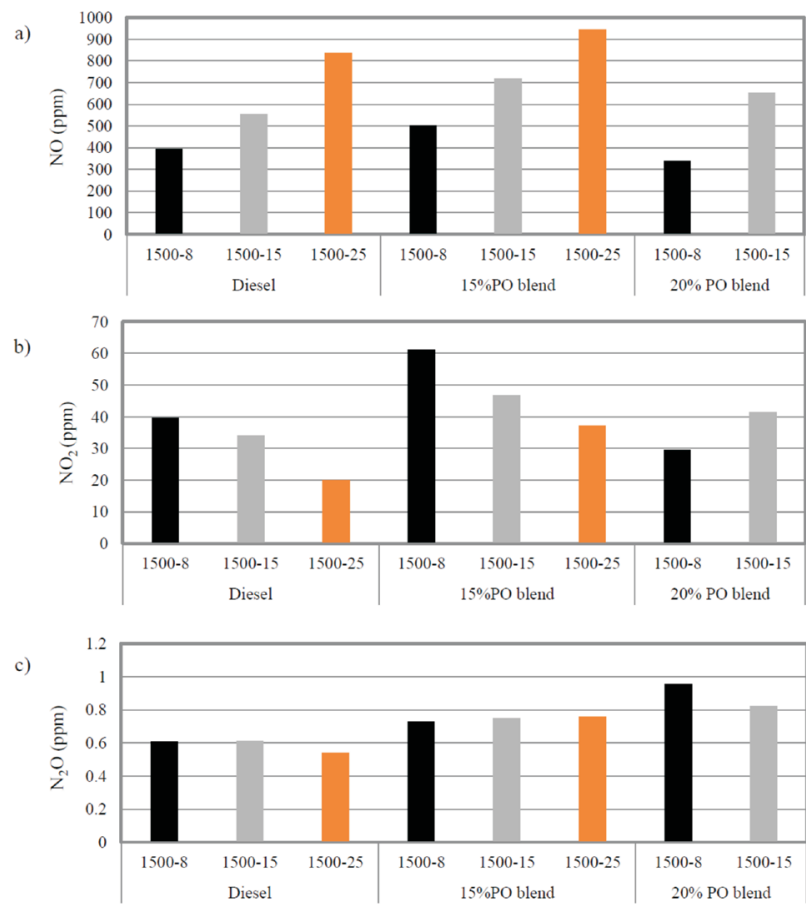

Fig. 9. Nitrogen emissions: a) $\mathrm{NO}, \mathrm{b}$ ) $\mathrm{NO} 2$ and c) $\mathrm{N} 2 \mathrm{O}$

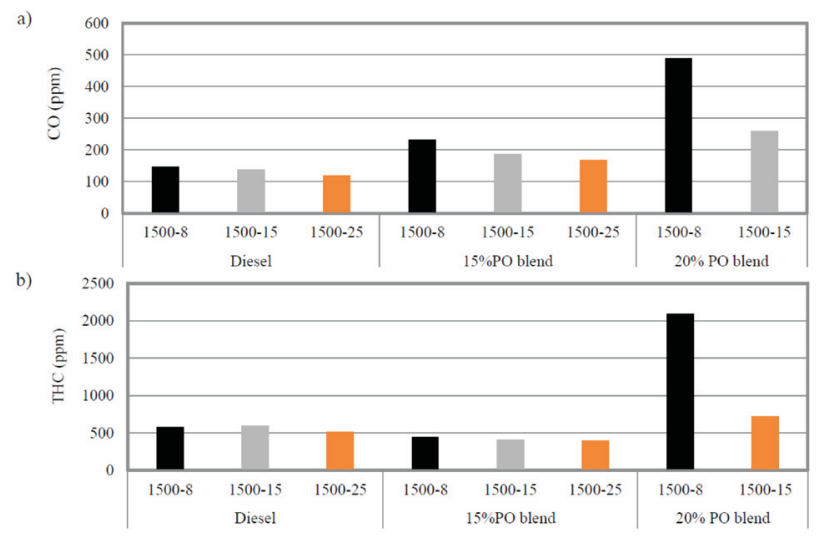

Fig. 10. Carbonaceous emissions

$15 \%$ PO combustion reduced slightly THC concentration. However, for the $20 \%$ PO blend the THC levels are increased significantly, particularly at low load. The lower in-cylinder temperature and the presence of heavy hydrocarbons in the fuel blend and therefore, higher viscosity can be disadvantageous for the liquid fuel spray patterns. The engine stopped during the $20 \%$ PO blend test and the engine could not be restarted until the injection system was cleaned using diesel. In addition, the fuel separation (tar layer at the bottom and a blend of the light hydrocarbons from the PO and diesel) observed in the tank can suggest that this fuel separation can also occurred during the injection process, meaning that: i) there is a fuel capable to provide normal operation of the engine and ii) there is a fuel with physical properties that are not optimum for internal combustion engines.

\subsection{Particulate Matter emissions}

Similar trends in PM emissions were obtained as well. Figure 11 shows the PM total number emissions for both PO blends and diesel baseline. The presence of PO aids in PM reduction, especially at higher loads, due to the presence of oxygen in the PO formula and the water cooling effect can also play an important role. However, at low loads PM total concentration was similar both diesel and PO blends.

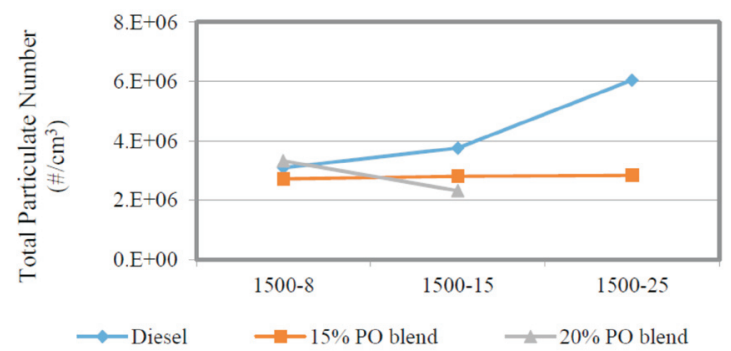

Fig. 11. PM total number

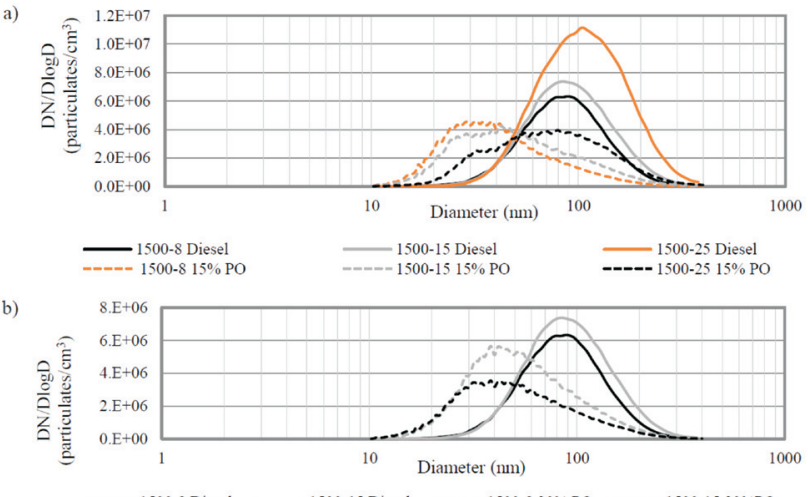

Fig. 12. PM emissions Batch (ii): a) 15\% PO blend and b) 20\% PO blend

Analysis the particulate size distribution (Figure 12), it can be observed that the PO blend reduced significantly larger particulates, accumulation mode, however, The combustion of both blends produced a peaks centred between $25-30 \mathrm{~nm}$ for $15 \%$ and $30-35 \mathrm{~nm}$ for the $20 \%$ blend. The size of these particulates suggests that they are composed mainly by heavy unburnt hydrocarbons. At the highest load, the PM diameters measured are similar to diesel particulates. Therefore, PO blend forms less soot, but the presence of heavy hydrocarbons in the base fuel increases the level of nucleation mode particulates (small PM).

\subsection{Fuel consumption}

The results for the fuel consumption are reported in Figure 13. Due to the lower heating value (high water content) the fuel consumption increased when using PO blends.

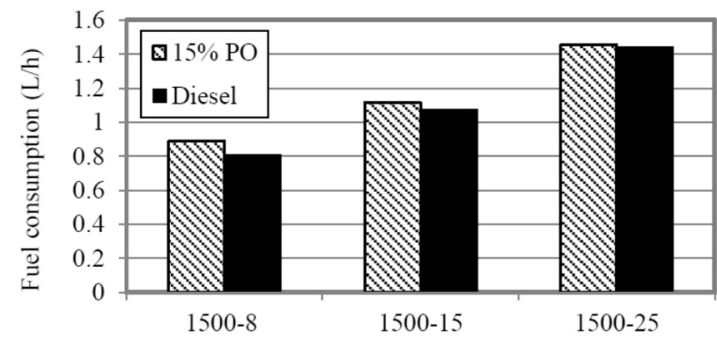

Fig. 13. Fuel consumption 


\subsection{Lubricity}

ULSD Sample which used as a Reference Diesel fuel is supplied by Shell Company by specified lubricity number. Its lubricity with ASTM D6079 Standard is $284 \mu \mathrm{m}$. A pre-test of lubricity for this fuel was performed three times, where results were 276,267 and $285 \mu \mathrm{m}$ and the average is given as a result in Table 5 .

Figure 14 is one sample of Wear Scar Diameter Measurement, which was repeated two times, and then average value is considered as a corrected wear scar diameter.

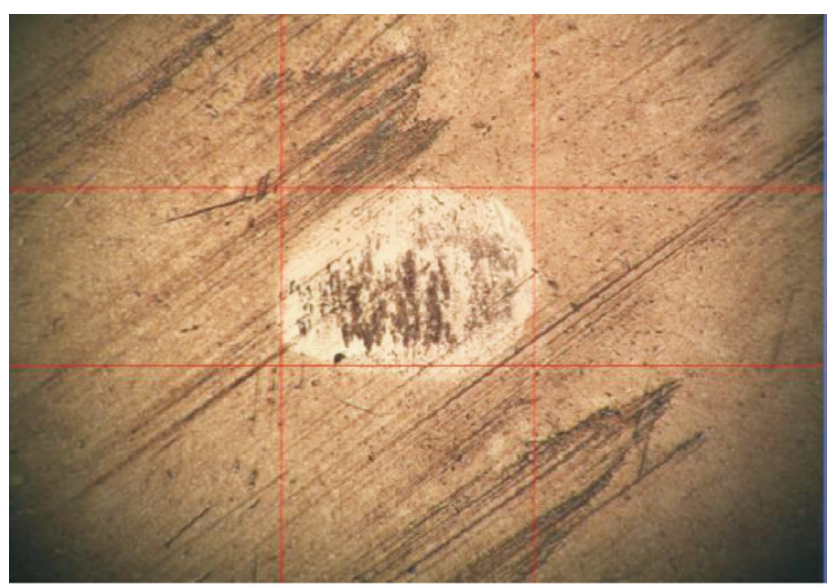

Fig. 14. Example of WSD $(\mu \mathrm{m})$

The lubrication properties of pyrolysis oil samples were investigated by using HFRR (PCS Instrument). Table 5indicates comparison of Lubricity properties of Pyrolysis oils compared to ULS Diesel Sample. Figure 15 shows the measured tribological properties obtained from the HFRR tests for the fuels. ULSD sample was tested three times for calibration and to investigate its accuracy. In addition, HFRR tests for PO blends were repeated twice and the mean value is reported. All fuels accomplished the ASTM D6079 Standard as all WSD were far below $520 \mu \mathrm{m}$.

Table 5. Corrected Wear Scar Diameter $(\mu \mathrm{m})$

\begin{tabular}{|l|c|}
\hline Fuel Types & Corrected Wear Scar Diameter $(\mu \mathrm{m})$ \\
\hline ULSD & 276 \\
\hline PO $15 \%$ Batch 1 & 314.5 \\
\hline PO 15\% Batch 2 & 281 \\
\hline PO 20\% Batch 2 & 186 \\
\hline
\end{tabular}

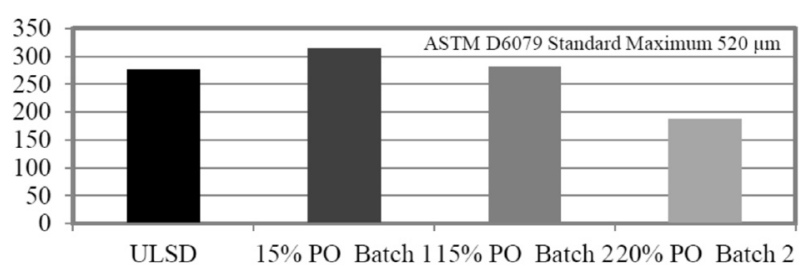

Fig. 15. Corrected Wear Scar Diameter $(\mu \mathrm{m})$

\section{Conclusions}

The feasibility of PO-diesel blends in a research single cylinder diesel engine has been investigated.
Gaseous emissions $\left(\mathrm{NO}_{\mathrm{x}}, \mathrm{CO}, \mathrm{THC}\right.$ and $\left.\mathrm{CO}_{2}\right)$ were generally increased with the increasing percentage of $\mathrm{PO}$ in the blended. Total PM emissions were reduced up to $52 \%$ at high loads, although no significant difference was observed at low loads. The presence of oxygen in the molecule can aid to reduce PM formation and promote PM oxidation during the expansion stroke. However, the increased levels of THC led to an increase in the nucleation mode. In addition, the COV and engine stability was deteriorated due to the higher viscosity and other physical properties of the fuel leading to high uncertainties in the results.

No significant differences were found in the WSD between $15 \%$ PO blend a diesel. A reduction of $32 \%$ in the WSD was observed for the $20 \%$ PO blend.

\section{Acknowledgements}

This work was supported by the Department of Energy and Climate Change through a cost shared grant from Phase 4 of the Energy Entrepreneurs Fund, with Future Blends Ltd (FBL). The authors thank Mr Nick Brooks, CEO of FBL for his support and encouragement throughout the project.

This project could not have been completed without the efforts of the FBL staff in producing the APO - Sanjeev Gajjela, Jose Medrano, Javier Gonzalez and Haonan Wu.

\author{
Abbreviations \\ 2-EHN 2-Ethyl Hexyl Nitrate \\ APOTM Advanced Pyrolysis Oil \\ bTDC Before Top Dead Centre \\ CAD Crank Angle Degree \\ COV Coefficient of Variance \\ HFRR High Frequency Reciprocating Rig \\ IMEP Indicated Mean Effective Pressure \\ PEG-400 Polyethylene Glycol 400 \\ PM Particulate Matter \\ PO Pyrolysis Oil \\ THC Total Hydrocarbons \\ ULSD Ultra Low Sulphur Diesel \\ WSD Wear Scan Diameter
}

\section{Bibliography}

[1] Gollakota, A.R.K. et al. A review on the upgradation techniques of pyrolysis oil. Renewable and Sustainable Energy Reviews, 2016;58:1543-1568.

[2] Kan, T., Strezov, V., Evans, T.J. Lignocellulosic biomass pyrolysis: A review of product properties and effects of pyrolysis parameters. Renewable and Sustainable Energy Reviews 2016;57:1126-1140.

[3] Lam, S.S. et al. Progress in waste oil to sustainable energy, with emphasis on pyrolysis techniques. Renewable and Sustainable Energy Reviews 2016;53:741-753.

[4] Goyal, H.B., Seal, D., Saxena, R.C. Bio-fuels from thermochemical conversion of renewable resources: A review. Renewable and Sustainable Energy Reviews 2008; 12(2):504-517.

[5] Papari, S., Hawboldt, K. A review on the pyrolysis of woody biomass to bio-oil: Focus on kinetic models. Renewable and Sustainable Energy Reviews 2015;52:1580-1595. 
[6] Sánchez, M.E. et al. Pyrolysis of agricultural residues from rape and sunflowers: Production and characterization of biofuels and biochar soil management. Journal of Analytical and Applied Pyrolysis 2009;85(1-2):142-144.

[7] Miskolczi, N. et al. Production of pyrolytic oils by catalytic pyrolysis of Malaysian refuse-derived fuels in continuously stirred batch reactor. Fuel Processing Technology 2011;92(5):925-932.

[8] Kim, T.Y., Lee, S., Kang, K. Performance and emission characteristics of a high-compression-ratio diesel engine fueled with wood pyrolysis oil-butanol blended fuels. Energy 2015;93:2241-2250.

[9] Mullen, C.A. et al. Bio-oil and bio-char production from corn cobs and stover by fast pyrolysis. Biomass and Bioenergy 2010;34(1):67-74.

[10] Thangalazhy-Gopakumar, S. et al. Physiochemical properties of bio-oil produced at various temperatures from pine wood using an auger reactor. Bioresour Technol. 2010;101(21):8389-95.

[11] Guo, Z., Wang, S., Wang, X. Stability mechanism investigation of emulsion fuels from biomass pyrolysis oil and diesel. Energy 2014;66:250-255.

Maria Bogarra-Macias, MEng. - Doctoral Research Student in the School of Engineering at University of Birmingham.

e-mail:mdb356@bham.ac.uk

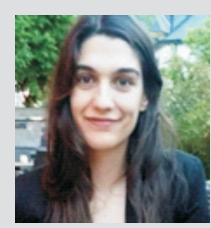

Mohammed A. Fayad - Doctoral Research Student in the School of Engineering at University of Birmingham.

e-mail:maf223@bham.ac.uk

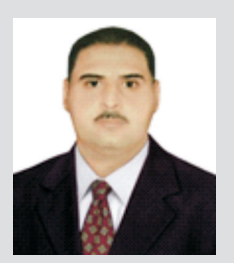

Athanasios (Thanos) Tsolakis, B.Eng, PhD, CEng, FIMechE, FHEA - Professor in School of Mechanical Engineering at University of Birmingham.

e-mail: a.tsolakis@bham.ac.uk

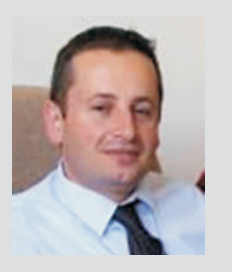

Andrzej Pacek, MEng, MSc, PhD - Professor in School of Chemical Engineering at University of Birmingham.

e-mail:a.w.pacek@bham.ac.uk

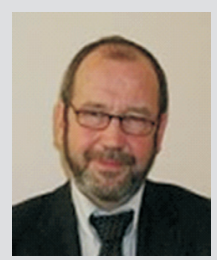

Ralph Overend, MSc, PhD - CTO at Future Blends Ltd.

e-mail: roverend@futureblends.com
[12] Zhang, Q. et al. Review of biomass pyrolysis oil properties and upgrading research. Energy Conversion and Management 2007;48(1):87-92.

[13] Ghannam, M.T., Selim, M.Y.E. Stability Behavior of Waterin-Diesel Fuel Emulsion. Petroleum Science and Technology 2009;27(4):396-411.

[14] Bridgwater, A.V. Principles and practice of biomass fast pyrolysis processes for liquids. Journal of Analytical and Applied Pyrolysis 1999;51:3-22.

[15] Yang, S.I. et al. Application of biomass fast pyrolysis part II: The effects that bio-pyrolysis oil has on the performance of diesel engines. Energy 2014;66:172-180.

[16] Hossain, A.K. et al. Combustion of fuel blends containing digestate pyrolysis oil in a multi-cylinder compression ignition engine. Fuel 2016;171:18-28.

[17] Sukjit, E. Synergistic effects of alcohol-based renewable fuels: fuel properties and emissions, PhD Thesis in School of Mechanical Engineering 2013, University of Birmingham, p. 171.

[18] Eslami, F. Properties, performance and emissions of biofuels in blends with gasoline. PhD Thesis in School of Engineering. 2013, The University of Birmingham, p. 139.

Omid Doustdar, MEng. - Doctoral Research Student in the School of Engineering at University of Birmingham.

e-mail: oxd021@bham.ac.uk

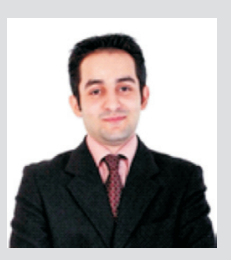

Miroslaw L Wyszynski, PhD. - Professor of Thermodynamics, in the School of Engineering, University of Birmingham.

e-mail: M.L.Wyszynski@bham.ac.uk

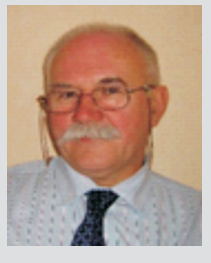

P Ding, PhD. - Research Fellow in School of Chemical Engineering, University of Birmingham.

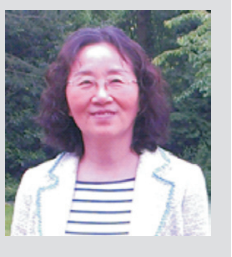

Peter Martin, MEng, PhD, CEng, MIChemE - Senior Lecturer in School of Chemical Engineering and Analytical Science at University of Manchester.

e-mail: pierre.comte@bfh.ch

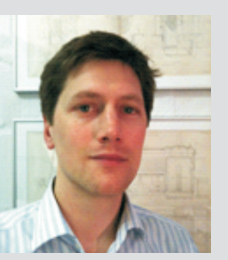

Shane O’Leary, BSc, PhD - Operations Manager at Future Blends Ltd.

e-mail: soleary@futureblends.com

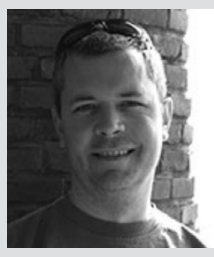

